Charting Self-Esteem During Marital Dissolution

Wiebke Bleidorn ${ }^{1}$, Ted Schwaba ${ }^{1}$, Jaap J.A. Denissen ${ }^{2}$, Christopher J. Hopwood ${ }^{1}$

${ }^{1}$ Department of Psychology, UC Davis

${ }^{2}$ Department of Developmental Psychology, Tilburg University

Correspondence concerning this article should be addressed to Wiebke Bleidorn, Department of Psychology, University of California Davis, One Shields Avenue, Davis, CA 95616, United States. E-mail: wiebkebleidorn@gmail.com

In press: Journal of Personality

Running head: SELF-ESTEEM AND MARITAL DISSOLUTION 


\begin{abstract}
Objective: The purpose of this study was to chart changes in self-esteem before and after marital dissolution to identify the factors that shape individuals' self-esteem during this life transition.
\end{abstract}

Method: We analyzed 10 annual waves of self-esteem data from 291 divorcees from a nationally representative panel study of the Netherlands $(N \sim 13,000)$. We charted the course of self-esteem before and after marital dissolution and tested a broad set of moderator variables that may shape individuals' self-esteem trajectories.

Results: The average divorcee experienced significant decreases in self-esteem preceding marital dissolution and remained stable afterwards. There were substantial individual differences in self-esteem trajectories, both before and after marital separation. Divorcees who experienced financial hardship, were affiliated with a church or religion, or scored low in conscientiousness showed the most pronounced decreases in self-esteem during the years approaching marital dissolution.

Conclusion: This study highlights the importance of assessing people multiple times before and after marital dissolution to dissect how people approach and respond to this life event. Results are consistent with perspectives that view divorce as an opportunity to abate the strains of an unhappy marriage. 
The dissolution of a marriage is associated with various psychological, social, and economic consequences, many of which are considered aversive, stressful, and potentially even traumatic (Amato \& Booth, 1991; Lucas, Clark, Georgellis, \& Diener, 2003). Indeed, most divorcees report lowered self-esteem and life-satisfaction, and increased depression and loneliness (Amato, 2000). Yet, the end of a marriage may also have positive consequences. In fact, some of the changes associated with marital dissolution may be viewed as opportunities to overcome the ongoing strains of an unhappy marriage and experience growth (Hawkins \& Booth, 2005). The degree to which individuals experience growth following marital dissolution may thus depend on the particular context and the presence of a variety of risk and protective factors (Lucas et al., 2003; Luciano \& Orth, 2017).

Longitudinal research supports the notion that individuals vary in their psychological reactions to marital dissolution (e.g., Denissen, Luhmann, Chung, \& Bleidorn, 2019; Lucas, 2005). However, little is known about the factors that shape individuals' self-esteem during the years leading up to and following marital dissolution. In the present study, we focus on the implications of marital dissolution for self-esteem. Specifically, we (1) chart the average selfesteem trajectory before and after marital dissolution, (2) examine individual differences in divorcees' self-esteem trajectories, and (3) explore a set of moderator variables that may shape individuals' self-esteem during this life transition.

\section{Self-Esteem During Marital Dissolution}

Self-esteem refers to individuals' subjective evaluation of their worth as a person and involves feelings of mastery, self-acceptance, and self-respect (Orth \& Robins, 2014). High levels of self-esteem have been associated with success in various life domains, including physical and 
mental health, educational and occupational attainment, and interpersonal success (Orth, Robins, \& Widaman, 2012).

The recognized importance of self-esteem for individuals and society has sparked research on the experiences that may shape and change self-esteem throughout the lifespan (e.g., Bleidorn et al., 2016a; Bleidorn et al., 2016b; Luciano \& Orth, 2017; Orth \& Robins, 2014; Orth, Trzesniewski, \& Robins, 2010). Several theories have emphasized the importance of interpersonal experiences for the development of self-esteem (e.g., Baumeister, 1998; Sullivan, 1953). Self-esteem has sometimes been described as a sociometer, referring to an internal measure that provides feedback regarding one's degree of social inclusion (Baumeister \& Leary, 1995). Consistent with this, young adults who start a romantic relationship, for example, have been found to increase in self-esteem, perhaps because they perceive themselves as worthy in their role as relationship partner (Lehnart, Neyer, \& Eccles, 2009).

Most existing research on life experiences and self-esteem has focused on normative life transitions, such as the transition to marriage, parenthood, college, or retirement (e.g., Chung et al; 2014; van Scheppingen, Denissen, Chung, Tambs, \& Bleidorn, 2018; Bleidorn \& Schwaba, 2018; Luciano \& Orth, 2017). This body of work suggests that people differ in their individual self-esteem trajectories during these transitions. For example, in a longitudinal study of over 84,000 mothers, van Scheppingen and colleagues found that the transition to parenthood was associated with an average decrease in self-esteem. Perhaps more interesting than this average trend, the self-esteem of some mothers decreased, the self-esteem of others increased, and some mothers' self-esteem remained stable during this life transition. These differences in individual self-esteem trajectories were correlated with mothers' perceived relationship quality. 
Specifically, those who reported higher relationship satisfaction with their romantic partner were less negatively impacted by the stressors associated with having a newborn.

In contrast to the growing literature on self-esteem during normative life events, few studies have examined self-esteem trajectories during non-normative and potentially aversive life transitions such as marital dissolution. One explanation for the relative sparseness of longitudinal research is that non-normative events tend to be rare and may be less predictable. For example, Luciano and Orth (2017) used data from over 9,000 young German adults to examine the associations between self-esteem and romantic relationship transactions. Even within this large sample, there were too few participants who experienced divorce during the 3year study period to examine this issue closely. Given the small sample size of divorcees, the authors focused on romantic relationship break-ups instead. Consistent with past research on stressful life experiences, they found that most participants who broke up with their partners decreased in self-esteem. However, this study also found significant individual differences in participants' self-esteem reactions to romantic break-ups. Specifically, participants who ended a relationship that had lasted for at least one year reported more pronounced declines in selfesteem compared to those who ended a shorter relationship.

Focusing on the consequences of unhappy marriages, Hawkins and Booth (2005) compared the self-esteem of individuals $(N=1,150)$ who reported that they had been unhappily married, continuously happily married, or divorced during a 12-year research period. Both happily married and divorced individuals reported significantly higher self-esteem at the end of the study period than unhappily married individuals. Although this study did not examine changes in self-esteem, divorce was interpreted as an opportunity to increase the 
well-being and self-esteem of unhappily married people. Again, this study found significant individual differences in this effect - both in magnitude and direction - suggesting that people differ in the ways in which they perceive, react to, and cope with an unsatisfying marriage.

The aforementioned research converges on at least three conclusions regarding the impact of marital dissolution on self-esteem. First, an individual's self-esteem appears to be malleable, especially in response to life events that involve interpersonal experiences such as parenthood or divorce. Second, although there is some evidence for decreases in self-esteem during romantic break-ups, some individuals might change differently than the norm. Third, the dissolution of an unhappy marriage can be associated with improved self-esteem. Together, these findings raise important questions about the specific factors that affect changes in selfesteem following the experience of marital dissolution. Two broader issues warrant particular considerations: time and context (cf. Bleidorn \& Schwaba, 2018). We next turn to these considerations.

\section{Time: Marital Dissolution as a Process}

Marital dissolution can be thought of as a process that begins while the couple lives together and ends well after the divorce is concluded (Amato, 2000). This process typically sets into motion numerous challenges, stressors, and opportunities, some of which may occur long before the marital separation or legal divorce whereas others tend to occur after the divorce. In fact, estranged or distressed couples often spend considerable time attempting to repair their relationship or avoiding their problems prior to divorce. Likewise, legal divorce does not always mark an end to the stressors and negative implications associated with marital dissolution but often presents new challenges such as financial changes, custody issues, changes in social 
networks, or moving. As such, there may be different psychological implications for the divorcing individual before and after the legal conclusion of a divorce (cf. Booth \& Amato, 1991).

Moreover, different factors may impact individuals' self-esteem before and after marital dissolution. For example, social support from family and friends may be an especially important resource for individual's well-being and self-esteem immediately after marital separation but may become less relevant as people adjust to their new situation or commit to a new romantic relationship (Amato, 2000). The recognition that different factors may shape self-esteem during different stages of marital dissolution implies the need for longitudinal data. In particular, a comprehensive understanding of the psychological implications of divorce requires multiple assessments during the years leading up to and following legal divorce (Amato, 2010).

To further strengthen the conclusions that can be drawn from longitudinal data, researchers need to distinguish between time-invariant and time-variant moderator variables that may shape self-esteem trajectories during divorce (Bleidorn \& Schwaba, 2018). Timeinvariant moderators, such as gender or religious affiliation (see below), are stable variables that have an enduring influence on individuals' self-esteem trajectories during marital separation. Time-variant moderators, such as income or personality traits, can change dynamically, and these changes must be considered when modeling associations with changes in self-esteem. Repeated assessments of these variables before and after marital dissolution are necessary to capture the dynamic nature of these moderators.

In summary, researchers must capture the process of marital dissolution and assess selfesteem and potential moderator variables multiple times to rigorously study the trajectory of 
self-esteem before and after this life event. In the present study, we address this issue for the first time to chart both the average self-esteem trajectory and individual differences in selfesteem change, both before and after marital dissolution.

\section{Context: Moderators of Self-Esteem Change During Marital Dissolution}

To understand the ways in which marital dissolution is associated with changes in selfesteem, researchers need to attend to the context in which this event occurs. A variety of risk and protective factors may shape individuals' self-esteem during the years leading up to and following marital separation. According to Amato (2000) and others, these factors can be classified as a) demographic, b) psychological, and c) interpersonal moderator variables (see Table 1).

Demographic Variables. We focus on six demographic variables that have been commonly discussed as potential moderators of psychological adjustment during marital dissolution: age, gender, the presence of children, education, employment, and financial hardship. Past studies yielded mixed results concerning the moderating role of age in people's responses to marital dissolution (Amato, 2000). Some researchers asserted that younger age may buffer people from the negative implications of marital dissolution, possibly because younger people have more opportunities to invest in new relationships (Amato \& Booth, 1991). Others argued that major life events, such as divorce, have more profound implications for young adults who tend to be generally more malleable in their personality and self-esteem than middle-aged or older adults (e.g., Bleidorn, Hopwood, \& Lucas, 2018). 
Similarly, little is known about the moderating role of gender in psychological adjustment to marital dissolution. While some scholars have suggested that women may be more affected by the stressors and stigma associated with divorce (cf. Amato, 2000), others argued that men should be more negatively affected because they tend to have fewer intimate and supportive relationships outside of their marriage (Costa, Herbst, McCrae, \& Siegler, 2000; Lucas, 2005). Again, the available data is inconclusive, leaving it open as to what degree men's and women's self-esteem may be differently affected during the process of marital dissolution (Williams \& Dunne-Bryant, 2006).

A commonly held assumption is that the presence of children has negative implications for adjustment during divorce, especially when custody negotiations and child care continue to remain sources of conflict between ex-spouses (Hetherington, Cox, \& Cox, 1982). However, some research indicated that children can provide a source of social support and sense of purpose, which may lead to enhanced psychological health and self-esteem during and following divorce (Amato, 2000; Wang \& Amato, 2000).

Employment status, level of income, and education have also been discussed as moderators of self-esteem change during marital dissolution (Amato, 2000). Divorce tends to negatively impact the standard of living for most people. However, those who are employed, especially in high-income jobs, are less likely to experience financial hardship and decreases in social status than those with a lower income. In addition to its obvious economic importance, employment can also provide an extra-familial source of mastery and self-worth (Wang \& Amato, 2000). Similarly, educational attainment may not only promote divorcees' adjustment via increased earning potential but has also been associated with a broader set of coping 
strategies, more options for alternative life plans, and larger social support networks (Amato \& Booth, 1991; Kitson \& Morgan 1990).

Psychological Variables. Existing research on psychological moderators of adjustment to divorce has largely focused on cognitive variables (Amato, 2000; 2010). Attitudes towards marriage and divorce, in particular, have been theorized to impact the ways people experience and cope with divorce. Consistent with this perspective, strong beliefs that marriage is a lifelong commitment have been found to predict higher levels of stress and poorer adjustment following divorce (Booth \& Amato, 1991; Simon \& Marcussen, 1999).

In a similar vein, religious beliefs have been hypothesized to shape adjustment to divorce (Krumrei, Mahoney, \& Pargament, 2011). However, whereas some scholars argued that divorcees experience enhanced stress to the degree that their religious affiliation and beliefs are incompatible with divorce (Lazarus \& Folkman, 1984), others consider religious engagement and spirituality as viable coping strategies when faced with divorce-related stress (Krumrei et al., 2011).

In addition, broad personality traits such as the Big Five (extraversion, neuroticism, conscientiousness, agreeableness, and openness; Goldberg, 1993; McCrae \& Costa, 1987) may shape people's self-esteem during aversive life events (e.g., Boyce \& Wood, 2010; Erol \& Orth, 2011; Solomon \& Jackson, 2014). Low neuroticism and high extraversion, in particular, are sometimes viewed as protective factors that may help individuals cope with stressful life transitions. Despite its theoretical appeal, this hypothesis has yet received limited empirical support (cf. Bleidorn \& Schwaba, 2018; Yap, Anusic, \& Lucas, 2012). However, no previous study 
has examined the moderating effects of Big Five traits on changes in self-esteem during marital dissolution.

Interpersonal Variables. The interpersonal situation of divorcees has been of particular interest to social scientists (Amato, 2000; 2010). Consistent with theory and research (Amato, 2000), we focus on three interpersonal moderators: marital investment, social support, and remarriage.

First, research suggested that the degree of marital investment can influence adjustment during divorce. For example, DeGarmo and Kitson (1996) found that adjustment was easier for women who were not heavily invested in their marital identity. Similarly, Wang and Amato found that post-divorce adjustment was more difficult for individuals who were married for longer periods of time (Wang \& Amato, 2000).

Second, most scholars view a large and supportive social network as an important resource during divorce. Many divorcees experience shifts and oftentimes declines in social network size, which may be associated with increased loneliness and decreases in self-esteem (Amato, 2000). Those who maintain close relationships with friends and family members or are able to form new connections should be better able to cope with the stressors associated with divorce and therefore experience a lesser decrement in their self-worth (Wang \& Amato, 2000).

Third, engaging in a new romantic relationship and remarrying have been associated with better adjustment among divorced individuals (Wang \& Amato, 2000). In addition to the intimacy and social support provided by a new partner, remarriage can also bring about an increase in income and standard of living (Amato, 2000). As such, investment in a new 
committed relationship may shield divorcees from some of the emotional, social, and financial stressors associated with divorce.

Overall, initial evidence suggests that interpersonal factors may play an important role in divorcees' adjustment - and potentially impact their self-esteem. This is consistent with major theories of self-esteem that emphasize the relevance of interpersonal experiences for adults' self-esteem development (e.g., Leary \& Baumeister, 2000). Research supports this notion, showing that changes in social support and relationship satisfaction are closely connected with changes in self-esteem (e.g., van Scheppingen et al., 2018). Consistent with this perspective, we expect these factors to moderate divorcees' self-esteem trajectories.

\section{The Present Study}

Over the past few decades, the broad and interdisciplinary literature on divorce has identified a list of potentially relevant variables that may shape individuals' self-esteem and overall well-being during marital dissolution (Amato, 2000; Lucas et al., 2003). However, existing research yielded mixed results regarding the relevance and role of demographic, psychological, and interpersonal variables. While some studies identified moderators of psychological adjustment during divorce, other studies provided conflicting or null results

(Amato, 2010; Booth \& Amato, 1991; Lucas, 2005; Wang \& Amato, 2000; Yap et al., 2012).

As with other research on adaptation to aversive life events (i.e., post-traumatic growth), the inconclusive nature of evidence may - at least in part - reflect methodological limitations of past research on marital dissolution (cf. Jayawickreme \& Blackie, 2014; Tennen \& Affleck, 2009). Prospective designs including multiple assessments of self-esteem and relevant 
moderator variables in sufficiently large samples of divorcees are needed to detect presumably small changes in self-esteem trajectories before with adequate statistical power. Past studies have often been constrained by cross-sectional designs or relatively small samples of divorcees (Amato, 2000; Luciano \& Orth, 2017). Although such studies can be useful to explore individual differences in self-esteem during marital dissolution, they do not afford the power to test interaction effects between potential moderatos and divorcee's adjustment before and after divorce.

In the present study, we sought to address these limitations by using multiple waves of data collected as part of a large-scale, nationally representative panel study. Specifically, we examined the course of self-esteem before and after the dissolution of marriage using 10 waves of longitudinal data from a representative sample of the Dutch population $(N \sim 13,000)$. In addition to charting the average self-esteem trajectory, we examined individual differences in self-esteem trajectories during the years leading up to and following divorce. We then explored a broad set of demographic, psychological, and interpersonal moderator variables that were selected based on previous theory and research for their potential to explain some of these differences (see Table 1). Through these analyses, we hope to provide a more complete understanding of the factors that shape individuals' self-esteem during marital dissolution and aid in developing interventions designed to promote self-esteem in divorcees.

\section{Method}

\section{Sample}

We used data from the Longitudinal Internet Studies for the Social Sciences (LISS;

Scherpenzeel, Das, Ester, \& Kaczmirek, 2010) panel which has followed a representative sample 
of the Dutch population from 2008 to 2018. LISS participants complete annual online surveys on various topics including their self-esteem. In addition, participants complete monthly surveys about their demographic status which we used to obtain information regarding their experience of marital dissolution. The initial cohort completed a self-esteem questionnaire on 8 occasions, in $2008,2009,2011,2013,2014,2015,2017$, and 2018 . A second cohort completed the self-esteem questionnaire on 7 occasions, in 2010, 2011, 2013, 2014, 2015, 2017, and 2018. A third cohort completed the self-esteem questionnaire on 6 occasions, in 2012, 2013, 2014, 2015, 2017, and 2018. A fourth cohort completed the self-esteem questionnaire in 2014,2015 , 2017, and 2018. All four cohorts completed each of the other surveys used in this study (work and school, health, income, and social integration and leisure) annually from 2008 to 2018 . The data used in the present study have been used, in part, in other published work. In four recent studies, we have used the LISS data to examine the associations between personality development and life experiences (Bleidorn \& Schwaba, 2018; Denissen et al., 2019; Schwaba \& Bleidorn, 2018; Schwaba \& Bleidorn, 2019; Schwaba, Luhmann, Chung, Denissen, \& Bleidorn, 2018). None of these works have analyzed changes in self-esteem as a function of separation and divorce, which is the focus of this manuscript.

\section{Participants}

In the present study, LISS participants who were divorced before and stayed divorced throughout the study period were excluded, as were participants who were younger than age 18 or who provided no data regarding their marital status or self-esteem. Of the remaining participants, we included those who indicated that a) they were married at some point during the study period and b) experienced divorce or separation from their marital partner at some 
point during the study period (the final sample included 9 participants who entered the study while divorced, but remarried and then divorced again during the study period). Applying these criteria resulted in a final sample of 291 participants (age at first assessment: $M=43.39, S D=$ 12.64) who experienced either divorce or marital separation during the study period. For each participant, data was centered at their month of divorce / marital separation. Specifically, we calculated, for each participant, a date of marital dissolution by identifying the month at which their demographic status changed from "married" to either "divorced" or "separated." We centered time, in months, around this variable, such that negative scores indicated months until divorce, and positive scores indicated months after divorce. Table 2 shows the available self-esteem reports per assessment wave as indicated by number of months before and after marital dissolution.

\section{Measures}

Self-Esteem. Self-esteem was measured using a 10-item version of the Rosenberg SelfEsteem Scale (Rosenberg, 1965). Responses were measured on a 7-point Likert scale, ranging from 1 (totally disagree) to 7 (totally agree). The scale's internal consistency (alpha) ranged from .88 to .91 across assessment waves. Table 2 shows the unstandardized mean-levels and standard deviations for self-esteem by months from divorce. To facilitate the interpretation of results of our main analyses, we standardized scores using the overall grand mean to a mean of 0 and a standard deviation of 1 .

Demographic Variables. We examined the moderating effects of six demographic variables: participants' gender $(0=$ female, $1=$ male), age (in years), presence of children $(0=$ no children, 1 = children present $)$, and level of education ( $0=$ no college, $1=$ college $)$ at the time of 
divorce as time-invariant moderator variables. We included financial hardship ("On a scale of 0 10, how hard how easy is it for you to live off your income?" 0 = very easy, 10 = very difficult) and employment status ("Are you currently in paid employment" $0=$ no, $1=$ yes) assessed prior and following divorce as time-variant moderator variables. Table 1 shows the descriptive statistics for all moderator variables.

Psychological Variables. To capture their dynamic nature, we assessed divorcees' attitudes towards marriage and divorce as time-variant moderators (see Table 1). Specifically, we examined participants' responses to three questions assessed before and after divorce: 1) Married people are generally happier than unmarried people (reverse coded), 2) A divorce is generally the best solution if a married couple cannot solve their marital problems, 3) It is all right for a married couple with children to get divorced ( $1=$ fully disagree $-5=$ fully agree). We initially planned to aggregate responses to these three questions but decided against this because responses to the first question were not strongly associated with answers to the second $(r=.13)$ and third question $(r=.15)$. We thus examined the first question as an indicator of positive attitudes towards marriage and the second and third question $(r=.50)$ as a two-item composite indicator of positive attitudes towards divorce.

We assessed whether participants were affiliated with a religion or church as a timeinvariant variable (Do you consider yourself a member of a certain religion or church community? $0=$ no, 1 = yes) and the frequency with which participants engaged in religious activities as a time-variant variable: "Aside from special occasions such as weddings and funerals, how often do you attend religious gatherings nowadays?" ( 1 = never -7 = everyday). 
The Big Five personality traits openness to experience, conscientiousness, extraversion, agreeableness, and emotional stability were assessed as time-variant moderators (pre- and post-divorce) using the 50-item International Personality Item Pool Big Five scale (IPIP-50, Goldberg, 1992). Each domain scale was assessed with 10 items and responses were made on 5-point Likert scale (1= very inaccurate -5 = very accurate).

Interpersonal Variables. We examined length of marriage in years as a time-invariant indicator of marital investment. We used the item: "How satisfied are you with your social contacts?" $(0=$ not at all satisfied $-10=$ completely satisfied $)$ to examine divorcees' satisfaction with their social contacts as a time-variant variable before and after divorce. We further assessed whether participants started a new romantic relationship after their divorce using the following item: "Do you currently have a partner? We understand a partner to be someone with whom you have been in a relationship for at least 3 months. This includes wedded partners." $(0=$ no, 1 = yes) and whether they remarried "Are you married to this partner?" $(0=$ no, $1=$ yes $)$. Both variables were assessed as post-divorce time-variant variables. We also examined the extent to which friends were shared between spouses before divorce using the following item: "Are the friends that you have mainly your own friends, or are they mainly friends that you share with your partner?" (1 = mainly own friends, 4 = mainly shared friends).

\section{Statistical Analyses}

We conducted multilevel model analysis with assessment waves nested within individuals using the package nlme (Pinhiero, Bates, DebRoy, \& Sarkar, 2014) in R version 3.3.3 (R core team, 2017). We visualized results using the R package ggplot2 (Wickham, 2016). To compare fits of nested models, we used -2 loglikelihood difference tests. To compare fits of 
non-nested models, we used the Bayesian Information Criterion (BIC; Duncan, Duncan, \& Strycker, 2013). Users with access to the LISS dataset can reproduce the analyses in this manuscript using code available at https://osf.io/y4bz9/

\section{Results}

\section{Self-Esteem Change Before and After Marital Dissolution}

We first estimated the average self-esteem trajectory before and after marital separation using piecewise growth curve modeling (cf. Bleidorn \& Schwaba, 2018). Specifically, to capture potentially different rates of change prior and post separation, we specified a multilevel model with three parameters: 1) an intercept reflecting participants' average predivorce levels of self-esteem, 2) a slope reflecting pre-divorce changes in self-esteem, and 3) a second slope reflecting post-divorce changes in self-esteem. Table 3 and Figure 1 show the results of this model (and raw data) suggesting that, on average, self-esteem decreases in the years before marital separation and is relatively stable afterwards.

To capture individual differences in self-esteem trajectories, we tested whether the inclusion of random effects improved overall model fit. Model comparison tests indicated that adding random effects for both the pre-divorce $(\Delta \chi 2(1)=17.59, p<.001)$ and post-divorce slope $(\Delta \times 2(1)=9.08, p=.003)$ led to significant increases in model fit, suggesting significant individual differences in self-esteem trajectories before and after marital separation (see Table 3).

\section{Moderators of Self-Esteem Change Before and After Marital Dissolution}


We extended the multilevel model described above by including each of the 20 moderator variables. Specifically, we estimated the association between each moderator and 1) the self-esteem intercept, 2) the pre-divorce slope, and the 3) post-divorce slope. To facilitate interpretation of these models, we z-standardized all non-binary moderators. To balance the risks of type-I and type-Il error, we report all associations that were significant at a $p$-value of $<.05$ in addition with 95\% confidence intervals and relevant effect size measures.

Table 4 shows the results for the moderator effects of pre-divorce and post-divorce changes in self-esteem. During the months approaching divorce, individuals who indicated that they were religious $(b=-0.003, p=.035)$, who experienced more financial hardship $(b=-0.002$, $p<.001)$, and were less conscientious $(b=0.004, p=.007)$, experienced more pronounced decreases in self-esteem (see Figure 2). None of the 21 variables we examined were significantly associated with post-divorce self-esteem trajectories (all $p$ s >= .05).

\section{Discussion}

Using 10-year longitudinal data, we charted the course of self-esteem before and after marital dissolution. Specifically, we estimated the average self-esteem trajectory before and after marital separation, quantified the amount of individual differences in self-esteem change, and tested the moderating effects of a broad set of demographic, psychological, and interpersonal variables on changes in self-esteem, both before and after marital dissolution.

Consistent with past research on divorce and romantic relationship break-ups (Amato, 2010; Luciano \& Orth, 2017), the average divorcee in our sample experienced significant decreases in self-esteem. Notably, these decreases occurred during the years approaching marital dissolution, came to a halt during the year of marital separation, and were followed by a 
stable trajectory during the years following marital dissolution. This discontinuous trajectory is consistent with perspectives that view divorce as an opportunity to overcome the ongoing strains of an unhappy marriage (Hawkins \& Booth, 2005). These perspectives hold that unhappy marital relationships expose individuals to ongoing stressors that negatively impacts their selfesteem. Marital separation may thus release spouses from the enduring stressors of an unhappy marriage and counteract self-esteem diminishing processes. As discussed above, marital separation may also be an opportunity to invest in other meaningful relationships with family, friends, or new relationship partners, which may provide new sources of support and counteract initial decreases in self-esteem (Amato, 2000).

However, in contrast to research on aversive life events and life satisfaction (e.g., Denissen et al., 2019; Luhmann, Hofmann, Eid, \& Lucas, 2012), we found no evidence for rebound effects suggesting that people do not increase to pre-existing self-esteem levels in the years following marital dissolution. In other words, the overall effects of marital stress and dissolution on self-esteem appear to be negative and enduring. More generally, the present results underscore the critical importance of assessing people multiple times before and after aversive life experiences to dissect how people approach and respond to such events (Luhmann et al., 2014). The majority of existing longitudinal studies on post-traumatic growth to date have been designed under the assumption that psychological change occurs after the experience of an aversive event. However, prospective designs including multiple pre-event assessments are needed to control for baseline differences and capture change that may occur in anticipation of an event (Bleidorn, Hopwood et al., 2019). 
Our study further highlighted large individual differences in self-esteem change during marital dissolution. Consistent with theory and past research, individuals varied significantly in their psychological reactions to divorce (Amato, 2000; Hawkins \& Booth, 2005; Lucas, 2005; Luciano \& Orth, 2017). Indeed, the present results indicated significant heterogeneity in individual trajectories both pre- and post-event, with some people decreasing and others increasing in self-esteem as they prepare for and adapt to marital dissolution. This finding adds to a growing body of evidence showing that aversive life events such as divorce can have different psychological implications for different people (Amato, 2010). These differences in development were apparent even before the event of marital separation. Whereas past research has generally focused on individual differences in adaptation after aversive life events (Jayawickreme, Rivers, \& Rauthmann, 2018), results of this study highlight how there also appear to be individual differences in the way that different people approach life events and their resilience during this approach period. It may be the case that some events are traumatic only for certain people and thus post-traumatic growth - if present - may only be observable among that subset of people. It may further be the case that only people with access to certain individual or contextual resources experience growth when faced with aversive life events. A major task for future research on post-traumatic growth will be to explain these individual differences in people's perceptions of and reactions to aversive life experiences such as divorce.

To begin to address this question and to gain a better understanding of the factors that shape people's self-esteem before and after marital separation, we examined the effects of demographic, psychological, and interpersonal moderator variables. Four findings stand out. First, we found little evidence for moderating effects of demographic variables except financial 
hardship. Consistent with theory and past research on divorce, individuals who described their financial situation as particularly difficult experienced more pronounced decreases in selfesteem - however, only during the years leading up to divorce. In contrast to perspectives that highlight the role of other demographic risk factors, we found no evidence for moderating effects of gender, age, education, employment, or the presence of children on either pre- or post-event changes in self-esteem. Second, we found some evidence for psychological risk factors that were associated with more pronounced decreases in self-esteem. Specifically, individuals with low (vs. high) levels of conscientiousness experienced more pronounced decreases in self-esteem during the years leading up to marital dissolution. This may suggest that more conscientious people may have access to better coping resources, such as investing in work or self-care, that cushion the impacts of marital dissolution. We further found that individuals who affiliated with a religion decreased more in self-esteem during the years approaching divorce. This finding is consistent with past research that showed that divorcees experience enhanced stress - and consequently diminished self-esteem - to the degree that their religious beliefs are incompatible with marital dissolution (Lazarus \& Folkman, 1984). Third, we found no evidence for moderating effects of any interpersonal resources or risk factors on either pre- or post-divorce changes in self-esteem. As we will explain in more detail below, this finding does not necessarily imply that interpersonal factors play no role in people's self-esteem during marital dissolution, but accounting for these differences may require larger and more diverse samples of divorcees.

\section{Limitations and Future Directions}


The strengths of the present study include a prospective 10-year longitudinal design, a representative sample, and advanced statistical techniques to model both average and individual self-esteem trajectories before and after marital separation. However, there are also important limitations. First, it is important to interpret the present findings with respect to a cultural, historical, and societal context. As this research was conducted in a sample representative of the population of the Netherlands, these results may not generalize to other contexts or groups in which marital dissolution may be a qualitatively different experience. Second, our focus on divorcees restricted our analyses to a - by contemporary standards moderate sample size. That is, a null moderator finding does not necessarily suggest that the variable does not moderate self-esteem changes during marital dissolution but rather that the effect of the moderator may have been too small to detect in the current analyses, particularly for variables with skewed distributions such as presence of children ( $84 \%$ of divorcees had children). Also, any effects observed in the present study should be replicated in independent and ideally larger samples. Third, our selection of moderators was meant to be broad but not exhaustive. Indeed, the process of marital dissolution may be associated with a host of other potentially relevant experiences such as moving out of one's home or exploring a new identity as single that may shape people's responses to this event. Moreover, the degree to which these experiences may elicit negative vs. positive changes in people's self-esteem may depend on a variety of other psychological factors that were not measured in this study. Fourth, we assessed global self-esteem with a common self-report measure but cannot rule out that other non-selfreport measures might lead to different results when applied to samples of divorcees. Future studies with larger samples from different cultures and different measures may thus reveal 
more or different resources and risk factors that shape people's self-esteem trajectories before and after marital dissolution.

\section{Conclusion}

We studied the course of self-esteem before and after the experience of marital dissolution. Consistent the view that divorce can be an opportunity to overcome the ongoing strains associated with an unhappy marriage, the average divorcee experienced significant decreases in self-esteem during the years leading up to divorce and remained stable in selfesteem in the years following this life transition. However, we found no evidence for rebound effects suggesting that people do not increase to pre-existing self-esteem levels in the years following marital dissolution. Not every divorcee followed these average trends as indicated by significant individual differences in divorcees' self-esteem trajectories - both before and after marital dissolution. Individual differences in pre-divorce changes were related to divorcees' demographic and psychological background. Specifically, those who experienced financial hardship, had a religious affiliation, or scored low in conscientiousness experienced more pronounced decreases in self-esteem during the years approaching marital dissolution. In contrast, we found little evidence for systematic influences that shaped divorcees' self-esteem after marital dissolution. This does not imply that demographic, psychological, or interpersonal differences play no role in people's pre- or post-divorce self-esteem trajectories but accounting for these differences may require larger and more diverse samples. More generally, the present results stress the importance of rigorous longitudinal designs, theoretically grounded assessment protocols, and large sample sizes to capture individual differences in the trajectories and timing of psychological change during aversive life experiences. 


\section{Declaration of Conflicting Interests}

The authors declare no potential conflicts of interest with respect to the research, authorship, and/or publication of this article.

\section{Funding}

The authors received no financial support for the research, authorship, and/or publication of this article. 


\section{References}

Amato, P. R. (2000). The consequences of divorce for adults and children. Journal of Marriage and Family, 62, 1269-1287.

Amato, P. R. (2010). Research on divorce: Continuing trends and new developments. Journal of marriage and family, 72(3), 650-666.

Amato, P. R., \& Booth, A. (1991). The consequences of divorce for attitudes toward divorce and gender roles. Journal of Family Issues, 12, 306-322.

Baumeister, R. F. (1998). The self. In Gilbert, S. Fiske, and G. Lindzey (eds.): The Handbook of Social Psychology (Vol. 1, 4th ed.), Boston, MA: McGraw-Hill.

Baumeister, R. F., \& Leary, M. R. (1995). The need to belong: desire for interpersonal attachments as a fundamental human motivation. Psychological Bulletin, 117, 497.

Bleidorn, W., Arslan, R. C., Denissen, J. J., Rentfrow, P. J., Gebauer, J. E., Potter, J., \& Gosling, S. D. (2016a). Age and gender differences in self-esteem-A cross-cultural window. Journal of Personality and Social Psychology, 111, 396-410.

Bleidorn, W., Buyukcan-Tetik, A., Schwaba, T., Van Scheppingen, M. A., Denissen, J. J., \& Finkenauer, C. (2016b). Stability and change in self-esteem during the transition to parenthood. Social Psychological and Personality Science, 7, 560-569.

Bleidorn, W., Hopwood, C. J. Back, M.D., Denissen J.J.A., Hennecke, M., Jokela, M., ... \& Zimmermann, J. (2019). The Personality Change Consortium - Establishing a framework for studying personality change.

Bleidorn, W., Hopwood, C. J., \& Lucas, R. E. (2018). Life events and personality trait change. Journal of Personality, 86, 83-96. 
Bleidorn, W., \& Schwaba, T. (2018). Retirement is associated with change in self-esteem. Psychology and Aging, 33, 586.

Boyce, C. J., \& Wood, A. M. (2011). Personality prior to disability determines adaptation: Agreeable individuals recover lost life satisfaction faster and more completely. Psychological Science, 22, 1397-1402.

Costa, P. T., Herbst, J. H., McCrae, R. R., \& Siegler, I. C. (2000). Personality at midlife: Stability, intrinsic maturation, and response to life events. Assessment, 7, 365-378.

Chung, J. M., Robins, R. W., Trzesniewski, K. H., Noftle, E. E., Roberts, B. W., \& Widaman, K. F. (2014). Continuity and change in self-esteem during emerging adulthood. Journal of Personality and Social Psychology, 106, 469-483.

Duncan, T. E., Duncan, S. C., \& Strycker, L. A. (2013). An introduction to latent variable growth curve modeling: Concepts, issues, and application. New York, Routledge Academic.

DeGarmo, D. S., \& Kitson, G. C. (1996). Identity relevance and disruption as predictors of psychological distress for widowed and divorced women. Journal of Marriage and the Family, 983-997.

Denissen, J. J. A., Luhmann, M., Chung, J. M., \& Bleidorn, W. (2019). Transactions between life events and personality traits across the adult lifespan. Journal of Personality and Social Psychology, 116, 612-633.

Erol, R. Y., \& Orth, U. (2011). Self-esteem development from age 14 to 30 years: A longitudinal study. Journal of Personality and Social Psychology, 101, 607-619.

Goldberg, L. R. (1992). The development of markers for the Big-Five factor structure. Psychological Assessment, 4, 26-42. 
Goldberg, L.R. (1993). The structure of phenotypic personality traits. American Psychologist, 48, 26-34.

Hawkins, D. N., \& Booth, A. (2005). Unhappily ever after: Effects of long-term, low-quality marriages on well-being. Social Forces, 84, 451-471.

Hetherington, E. M., Cox, M., \& Cox, R. (1982). Effects of divorce on parents and children. In M. E. Lamb (Ed.), Nontraditional Families (pp. 233-288). Hillsdale, NJ: Erlbaum.

Jayawickreme, E., \& Blackie, L. E. (2014). Post-traumatic growth as positive personality change: Evidence, controversies and future directions. European Journal of Personality, 28, 312331.

Jayawickreme, E., Rivers, J., \& Rauthmann, J. M. (2018). Do We Know How Adversity Impacts Human Development?. Research in Human Development, 15, 294-316.

Kitson, G. C., \& Morgan, L. A. (1990). The multiple consequences of divorce: A decade review. Journal of Marriage and Family, 52, 913-924.

Krumrei, E. J., Mahoney, A., \& Pargament, K. I. (2011). Spiritual stress and coping model of divorce: A longitudinal study. Journal of Family Psychology, 25, 973-985.

Lazarus, R. S., \& Folkman, S. (1984). Stress, appraisal, and coping. New York: Springer.

Leary, M. R., \& Baumeister, R. F. (2000). The nature and function of self-esteem: Sociometer theory. In: Advances in experimental social psychology (Vol. 32, pp. 1-62). Academic Press.

Lehnart, J., Neyer, F. J., \& Eccles, J. (2010). Long-term effects of social investment: The case of partnering in young adulthood. Journal of Personality, 78, 639-670. 
Lucas, R. E. (2005). Time does not heal all wounds: A longitudinal study of reaction and adaptation to divorce. Psychological Science, 16, 945-950.

Lucas, R. E., Clark, A. E., Georgellis, Y., \& Diener, E. (2003). Reexamining adaptation and the set point model of happiness: reactions to changes in marital status. Journal of Personality and Social Psychology, 84, 527-539

Luciano, E. C., \& Orth, U. (2017). Transitions in romantic relationships and development of selfesteem. Journal of Personality and Social Psychology, 112, 307-328.

Luhmann, M., Hofmann, W., Eid, M., \& Lucas, R. E. (2012). Subjective well-being and adaptation to life events: a meta-analysis. Journal of Personality and Social Psychology, 102, 592.

Luhmann, M., Orth, U., Specht, J., Kandler, C., \& Lucas, R. E. (2014). Studying changes in life circumstances and personality: It's about time. European Journal of Personality, 28, 256266.

McCrae, R. R., \& Costa, P. T. (1987). Validation of the five-factor model of personality across instruments and observers. Journal of Personality and Social Psychology, 52, 81-90.

Orth, U., \& Robins, R. W. (2014). The development of self-esteem. Current Directions in Psychological Science, 23, 381-387.

Orth, U., Robins, R. W., \& Widaman, K. F. (2012). Life-span development of self-esteem and its effects on important life outcomes. Journal of Personality and Social Psychology, 102, 1271-1288.

Orth, U., Trzesniewski, K. H., \& Robins, R. W. (2010). Self-esteem development from young adulthood to old age: A cohort-sequential longitudinal study. Journal of Personality and Social Psychology, 98, 645-658. 
Pinheiro, J., Bates, D., DebRoy, S., \& Sarkar, D. (2014). R Core Team (2014) nlme: linear and nonlinear mixed effects models. R package version 3.1-117. Available at $\mathrm{h}$ ttp://CRAN. Rproject. org/package $=$ nlme

Scherpenzeel, A., Das, J. W. M., Ester, P., \& Kaczmirek, L. (2010). 'True' longitudinal and probability-based internet panels: Evidence from the Netherlands. In M. Das, P. Ester, \& L. Kaczmirek (eds). Social and Behavioral Research and the Internet: Advances in applied methods and research strategies. New York: Routledge. 77-103.

Schwaba, T., \& Bleidorn, W. (2018). Individual differences in personality change across the adult life span. Journal of Personality, 86, 450-464.

Schwaba, T. \& Bleidorn, W. (2019). Personality development across the transition to retirement. Journal of Personality and Social Psychology, 116, 651-665.

Schwaba, T., Luhmann, M., Denissen, J. J. A., Chung, J. M., \& Bleidorn, W. (2018). Openness to experience and culture-openness transactions across the lifespan. Journal of Personality and Social Psychology, 115, 118-136.

Simon, R. W., \& Marcussen, K. (1999). Marital transitions, marital beliefs, and mental health. Journal of Health and Social Behavior, 40, 111-125.

Solomon, B. C., \& Jackson, J. J. (2014). Why do personality traits predict divorce? Multiple pathways through satisfaction. Journal of Personality and Social Psychology, 106, 978996.

Sullivan, H. S. (1953). The interpersonal theory of psychiatry. New York: Norton.

Tennen, H., \& Affleck, G. (2009). Assessing positive life change: In search of meticulous methods. In C. L. Park, S. C. Lechner, M. H. Antoni, \& A. L. Stanton (Eds.), Medical illness 
and positive life change: Can crisis lead to personal transformation? (pp. 31-49).

Washington, DC, US: American Psychological Association.

van Scheppingen, M. A., Denissen, J. J. A., Chung, J. M., Tambs, K., \& Bleidorn, W. (2018). Selfesteem and relationship satisfaction during the transition to motherhood. Journal of Personality and Social Psychology, 114, 973-991.

Wang, H., \& Amato, P. R. (2000). Predictors of divorce adjustment: Stressors, resources, and definitions. Journal of Marriage and Family, 62, 655-668.

Wickham, H. (2016). ggplot2: Elegant Graphics For Data Analysis. New York: Springer.

Williams, K., \& Dunne-Bryant, A. (2006). Divorce and adult psychological well-being: Clarifying the role of gender and child age. Journal of Marriage and Family, 68, 1178-1196.

Yap, S. C., Anusic, I., \& Lucas, R. E. (2012). Does personality moderate reaction and adaptation to major life events? Evidence from the British Household Panel Survey. Journal of Research in Personality, 46, 477-488. 
Table 1. Moderator variables.

\begin{tabular}{|c|c|c|c|c|c|c|c|}
\hline \multirow[t]{2}{*}{ Moderator } & \multirow{2}{*}{$\begin{array}{c}\text { Time- } \\
\text { invariant }\end{array}$} & \multicolumn{2}{|c|}{ Time-variant } & \multirow[b]{2}{*}{ Scale } & \multicolumn{3}{|c|}{$1^{\text {st }}$ wave } \\
\hline & & Pre & Post & & $M$ & SD & $\%$ \\
\hline \multicolumn{8}{|l|}{ Demographic variables } \\
\hline Age & $x$ & & & years & 43.39 & 12.64 & \\
\hline Financial Hardship & $x$ & $x$ & $x$ & $0-10$ & 3.92 & 2.24 & \\
\hline Male & $x$ & & & $y / n$ & & & 46 \\
\hline Children & $x$ & & & $y / n$ & & & 84 \\
\hline College & $x$ & & & $y / n$ & & & 32 \\
\hline Employment & & $x$ & $x$ & $y / n$ & & & 74 \\
\hline \multicolumn{8}{|l|}{ Psychological variables } \\
\hline Attitudes towards marriage & & $x$ & $x$ & $1-5$ & 2.69 & 1.02 & \\
\hline Attitudes towards divorce & & $x$ & $x$ & $1-5$ & 2.41 & 0.79 & \\
\hline Emotional stability & & $x$ & $x$ & $1-5$ & 3.32 & 0.72 & \\
\hline Extraversion & & $x$ & $x$ & $1-5$ & 3.29 & 0.66 & \\
\hline Openness & & $x$ & $x$ & $1-5$ & 3.61 & 0.49 & \\
\hline Agreeableness & & $x$ & $x$ & $1-5$ & 3.93 & 0.49 & \\
\hline Conscientiousness & & $x$ & $x$ & $1-5$ & 3.71 & 0.55 & \\
\hline Religious engagement & $x$ & & & $1-7$ & 1.95 & 1.35 & \\
\hline Religious affiliation & $x$ & & & $y / n$ & & & 35 \\
\hline \multicolumn{8}{|l|}{ Interpersonal factors } \\
\hline Length of marriage & $x$ & & & years & 18.45 & 12.56 & \\
\hline Satisfaction with social life & & $x$ & $x$ & $1-10$ & 6.94 & 1.91 & \\
\hline Shared friends & & $x$ & & $1-4$ & 2.65 & 0.99 & \\
\hline New partner & & & $x$ & $y / n$ & & & 41 \\
\hline Remarried & & & $x$ & $y / n$ & & & 23 \\
\hline
\end{tabular}

Note. Descriptives refer to first assessment wave. All $y / n$ questions were coded $n=0, y=1$. Pre $=$ potential moderators of self-esteem change before marital dissolution; Post $=$ potential moderators of self-esteem change after marital dissolution. 
Table 2. Sample sizes and descriptives for self-esteem by months divorced / separated.

\begin{tabular}{|c|c|c|c|c|c|c|c|c|c|c|c|}
\hline $\begin{array}{l}\text { Months from } \\
\text { divorce/separation }\end{array}$ & $\begin{array}{l}-124 \text { to } \\
-100\end{array}$ & $\begin{array}{l}-99 \text { to } \\
-80\end{array}$ & $\begin{array}{l}-79 \text { to } \\
-60\end{array}$ & $\begin{array}{l}-59 \text { to } \\
-40\end{array}$ & $\begin{array}{l}-39 \text { to } \\
-20\end{array}$ & $\begin{array}{l}-19 \text { to } \\
0\end{array}$ & $\begin{array}{l}+1 \text { to } \\
+20\end{array}$ & $\begin{array}{l}+21 \text { to } \\
+40\end{array}$ & $\begin{array}{l}+41 \text { to } \\
+60\end{array}$ & $\begin{array}{l}+61 \text { to } \\
+80\end{array}$ & $\begin{array}{l}+81 \text { to } \\
+115\end{array}$ \\
\hline$N$ & 52 & 68 & 112 & 169 & 202 & 225 & 192 & 135 & 85 & 54 & 40 \\
\hline$M$ & 5.74 & 5.54 & 5.47 & 5.44 & 5.49 & 5.35 & 5.28 & 5.28 & 5.37 & 5.50 & 5.32 \\
\hline$S D$ & 0.96 & 1.09 & 1.00 & .95 & 1.02 & 1.05 & 1.07 & 1.09 & 1.00 & 1.04 & 1.09 \\
\hline
\end{tabular}

Note. Data was centered on month of marital dissolution. 
Table 3. Changes in self-esteem before and after marital dissolution.

\begin{tabular}{lrcrcc}
\hline Parameter & \multicolumn{1}{l}{ B } & \multicolumn{1}{c}{$95 \% \mathrm{Cl}$} & \multicolumn{1}{c}{$p$} & Random effects & $95 \% \mathrm{Cl}$ \\
\hline Intercept & -0.072 & {$[-0.190,0.012]$} & .659 & 0.896 & {$[0.805,0.995]$} \\
Pre-divorce linear change & -0.003 & {$[-0.005,-0.003]$} & $<.001$ & 0.008 & {$[0.006,0.011]$} \\
Post-divorce linear change & 0.000 & {$[-0.002,0.001]$} & .714 & 0.008 & {$[0.005,0.011]$} \\
\hline
\end{tabular}

Note. Self-esteem was standardized to a $\mathrm{M}$ of 0 and a SD of 1 . Change reflects SD units per month. Level shift at month of marital dissolution was modeled as a fixed effect. 
Table 4. Moderators of self-esteem change during 10 years leading up to and following marital dissolution.

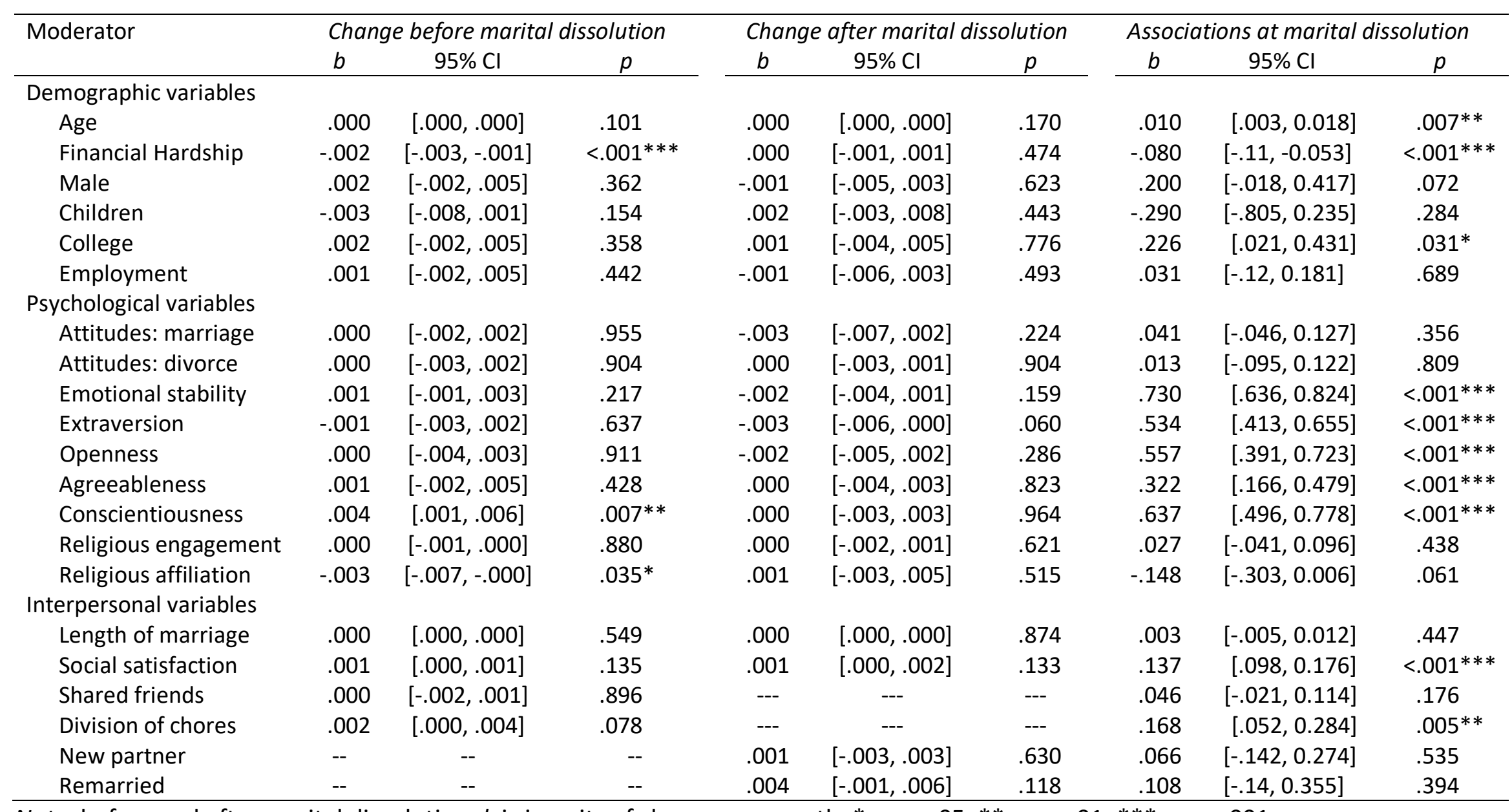

Note. before and after marital dissolution, $b$ is in units of change per month. ${ }^{*}=p<.05,{ }^{* *}=p<.01,{ }^{* *}=p<.001$. 
Figure 1. Self-esteem development before and after marital dissolution.

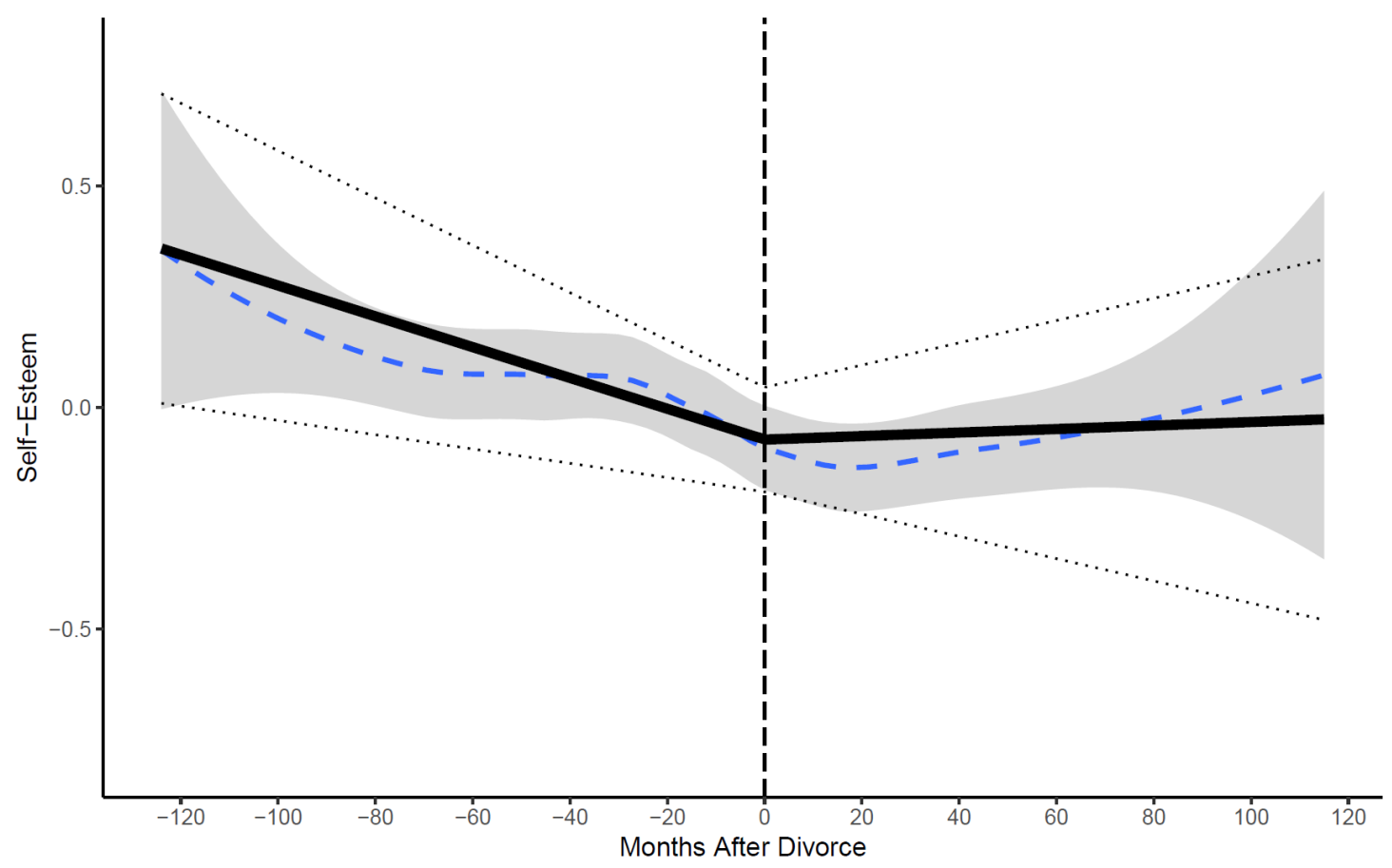

Note. The solid line represents developmental estimates from the multilevel model. The dotted lines represent $95 \%$ confidence intervals around the model-implied trajectories. The dashed line represents raw LOESS-smoothed mean-levels over time. The gray shaded area represents the $95 \%$ confidence interval of the LOESS-smoothed trajectory. Pre-divorce change is significant at $p<.001$. 

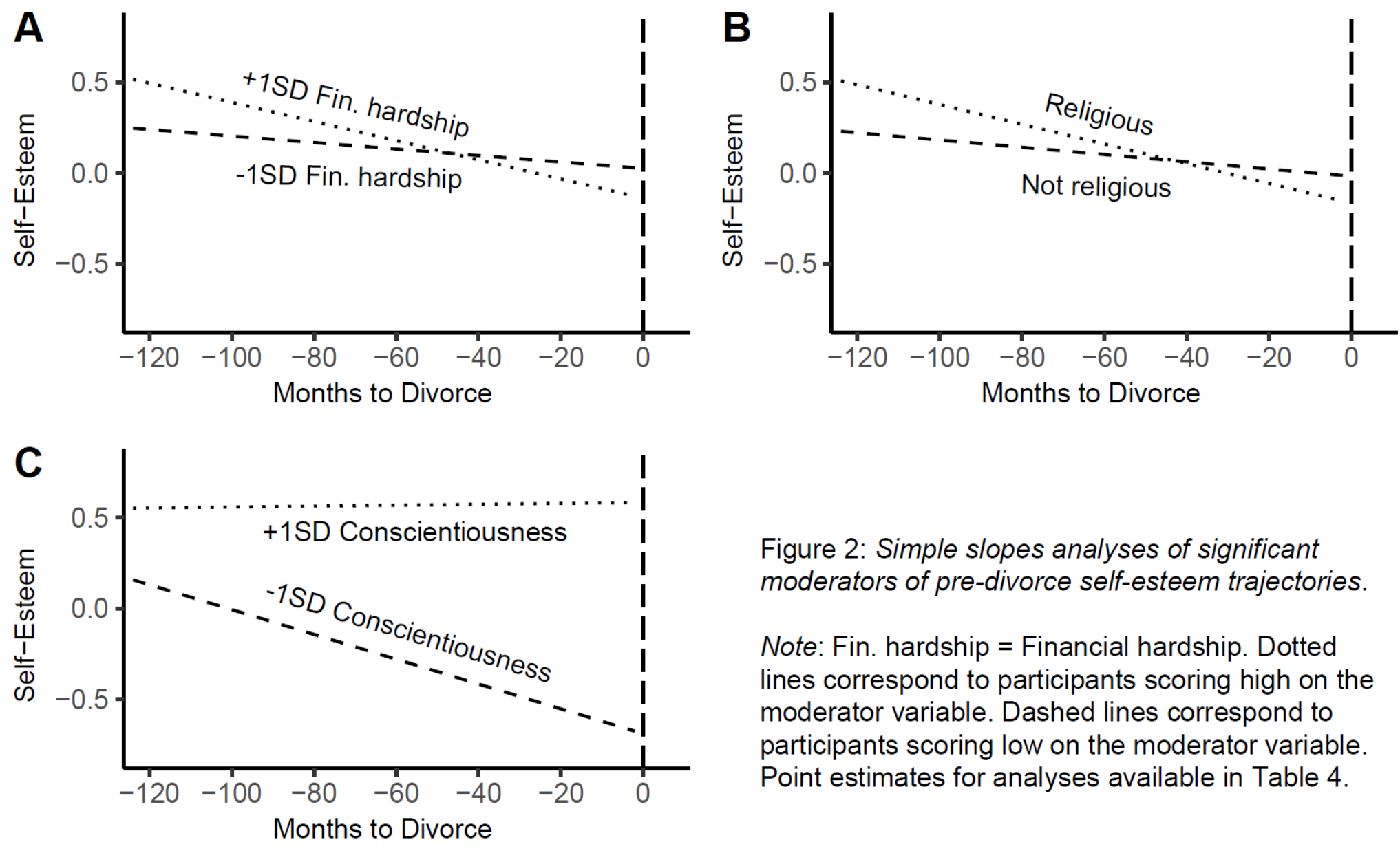

Figure 2: Simple slopes analyses of significant moderators of pre-divorce self-esteem trajectories.

Note: Fin. hardship = Financial hardship. Dotted lines correspond to participants scoring high on the moderator variable. Dashed lines correspond to participants scoring low on the moderator variable. Point estimates for analyses available in Table 4. 